\title{
Total arsenic and speciation analysis of saliva and urine samples from individuals living in a chronic arsenicosis area in China
}

Dapeng Wang ${ }^{1,2}$, Yasuyo Shimoda ${ }^{3}$, Sanxiang Wang ${ }^{4}$, Zhenghui Wang ${ }^{4}$, Jian Liu', Xing Liu', Huanyu Jin', Fenfang Gao', Jian Tong ${ }^{1}$, Kenzo Yamanaka ${ }^{3}$, Jie Zhang ${ }^{1 *}$ and Yan $\mathrm{An}^{1 *}$

\begin{abstract}
Background: It is generally acknowledged that the determination of harmful chemical compounds excreted into saliva is useful for assessing their exposure levels. The aim of the present study was to compare the total arsenic and its species in saliva and urine samples collected from the people residing in an arsenic-contaminated area of China and to further verify the feasibility of using salivary arsenic as a new biomarker of arsenic exposure.

Methods: Total arsenic and speciation analyses in urine and saliva samples among 70 residents exposed to arsenic from drinking water in Shanxi, China were carried out by high-performance liquid chromatography-inductively coupled plasma-mass spectrometry (HPLC-ICP/MS).

Results: The result showed that, total arsenic concentration in saliva was relatively lower than in urine samples, but it existed a strong positive correlation with total urinary arsenic, drinking water arsenic and different skin lesions. For arsenic metabolism analyses, $A s^{\prime \prime \prime}, A s^{V}, M M A$, and DMA were detected in all of the urine samples with the dominating species of DMA (73.2\%). Different with urinary arsenic species, most arsenic species in saliva were not methylated. The major species in saliva was iAs (As'l| $\left.+A s^{\vee}, 76.18 \%\right)$, followed by DMA (13.08\%) and MMA (9.13\%). And the primary methylation index $(\mathrm{PMI})$, second methylation index (SMI) and proportion of the four different species ( $\mathrm{As} \mathrm{I}^{\mathrm{II}}, \mathrm{As}^{\mathrm{V}}, \mathrm{MMA}$, and $\mathrm{DMA}$ ) in saliva showed no significant positive relationship with that of in urine.

Conclusions: These findings indicated saliva may be used as a useful tool for biological monitoring of total arsenic exposure in the crowd rather than an efficient tool for assessing arsenic metabolism in human body after exposed to arsenic.
\end{abstract}

Keywords: Arsenic speciation, Saliva, Urine, Drinking water, Biomarker

\section{Background}

Arsenic is a ubiquitous element in the earth's crust [1] and is widely distributed in water, air, soil, and food in both inorganic and organic forms [2]. Inorganic arsenic (arsenate and/or arsenite) has long been recognized as human carcinogens by the International Agency for Research on Cancer (IARC) [3]. Long-term exposure to inorganic arsenic can cause numerous human health effects, including several types of cancers [3-5], cardiovascular disease, and diabetes [6,7]. In addition, arsenicosis is a serious and

\footnotetext{
*Correspondence: zhangjie_78@suda.edu.cn; dranyan@126.com

'Department of Toxicology, School of Public Health, Jiangsu Key Laboratory

of Preventive and Translational Medicine for Geriatric Diseases, Medical

College of Soochow University, Suzhou, Jiangsu 215123, People's Republic of China

Full list of author information is available at the end of the article
}

widespread global public health problem [8] with more than 200 million people at risk of toxic arsenic exposure from ground water and food contamination [9]. Considerable progress has been made in recent years to address arsenic toxicity, including both genetic and epigenetic alteration $[10,11]$. In spite of these efforts, the exact molecular and cellular mechanism involved in arsenic toxicity are rather unrevealed given that the complicated metabolism of arsenic in the human body, and no effective treatment for arsenicosis exists [3]. Hence, timely screening for arsenic exposure and accessing arsenic metabolism is particularly vital in preventing arsenic poisoning. Traditionally, samples for screening arsenic exposure mainly include blood, urine, hair, and nails [12, 13]. More recently, salivary analyses has became a useful tool for 
disease diagnosis because of its non-invasive collection method and easy storage [14]. Additionally, in the area of biological monitoring, previous studies on the use of saliva have focused on lead, cadmium, mercury, and herbicide concentrations in humans or animals [15-19]. For arsenic exposure, there have been limited and paradoxical studies that have detected arsenic concentration in saliva. Yuan et al., [20] first analyzed arsenic and its species in human saliva from an arsenic-contaminated area and found that salivary arsenic could be a potential biomarker of arsenic exposure. Subsequently, other studies carried out in India and Thailand had shown that total arsenic concentrations in saliva have an evident positive correlation with the total arsenic levels both in urine and drinking water [21, 22]. In a different study, Lew et al. [23] did not find any significant differences in the concentration or speciation of arsenic in saliva samples from children that were exposed to arsenic by playing in Chromated Copper Arsenate (CCA) treated wood playground compared to those that did not play in CCA-treated wood. Moreover, some researchers believed that the low concentration of arsenic and small variations made salivary arsenic unsuitable as a biomarker of arsenic exposure [24]. Hence, whether or not saliva can be used as an efficient tool for biological monitoring of arsenic exposure, especially for assessing arsenic species remains to be further verified. The aim of the present study, therefore, was to compare the total arsenic and its species in saliva and urine samples collected from the people residing in an arsenic-contaminated area of China and to further verify the feasibility of using salivary arsenic as a new biomarker of arsenic exposure.

\section{Methods \\ Study population}

The National Diagnosis Standard for Endemic Arsenism (WS/T211-2001) [25], was used by trained biomedical personnel from Shanxi Institute for Prevention and Treatment of Endemic Disease to identify and categorize cases of arsenicosis during the survey. According to our previous survey data $[26,27]$, we chose 42 families (total of 70 individuals) from 4 villages in an endemic arsenicosis area in Shanyin County, Shanxi Provence, China, as subjects, and then collected well water samples from all families, and urine and saliva samples from all individuals. This study was approved by the Ethics Committee of the School of Public Health, Medical College of Soochow University according to the recommendations of the World Medical Association Declaration of Helsinki Ethical Principles [28] for international health research. All participants provided informed consent before participating.

\section{Sample collection}

Water samples were collected from all the families into polyethylene bottles rinsed beforehand with dilute nitric acid and then $5 \sim 6$ drops of $30 \%$ nitric acid were added to maintain the $\mathrm{pH}$ value below two. Urine samples were collected into disposable plastic cups and then dispensed into $50 \mathrm{~mL}$ polyethylene centrifugal tubes cleaned with dilute nitric acid and kept on ice. The saliva samples were collected at least $1 \mathrm{~h}$ after any food consumption, before collection, participants were told to rinse their mouths at least 3 times to remove any food residue, then threw away some of the initial saliva, collected $2 \mathrm{~mL}$ of the saliva into centrifuge tubes and kept on ice. All samples were stored at $-80{ }^{\circ} \mathrm{C}$ until analysis.

\section{Chemicals}

Analytical grade reagents were used throughout. Arsenic standard solution for atomic absorption spectrometry $(1000 \mu \mathrm{g} / \mathrm{mL})$, the chemical standards of sodium arsenite $\left(\mathrm{As}^{\mathrm{III}}\right)$, sodium arsenate $\left(\mathrm{As}^{\mathrm{V}}\right)$, methylarsonic acid (MMA), arsenobetaine (AsBe) were purchased from Wako Pure Chemical Industries, Ltd. (Osaka, Japan). Dimethylarsinate (DMA) was obtained from Tri Chemical Laboratory (Yamanashi, Japan). Germanium standard solution (Kanto Chemical, Tokyo, Japan) was used as internal standard for HPLC-ICP/MS analysis. Nitric acid (HNO3, Wako Pure Chemical, Osaka, Japan) was used for sample treatment. Ammonium bicarbonate (NH4HCO3, Bio Ultra, Sigma-Aldrich, St. Louis, MO, USA) and methanol (for high performance liquid chromatography, Wako Pure Chemical, Osaka, Japan) was used for the mobile phase of HPLC. Tap water was purified through MilliQ Plus (Millipore Japan, Tokyo, Japan). The certified reference material, NIES CRM No. 18 (human urine), from the National Institute for Environmental Studies (Ibaraki, Japan) was used to validate the analytical procedure.

\section{Sample preparation and total arsenic detection}

For water samples, $1 \mathrm{~mL}$ of them was aspirated into polyethylene centrifugal tubes and then $5 \mathrm{~mL}$ of $\mathrm{HCl}$ and $5 \mathrm{~mL}$ of $2 \%$ thiourea-ascorbic acid mixture were added to produce the final volume, an Atomic Fluorescence Spectrometer (AFS-230, Beijing Kechuang Haiguang Instrument Corporation, China) was used for total arsenic detection.

The urine and saliva samples were diluted three-fold with $0.1 \mathrm{M}$ nitric acid and centrifuged at $3000 \mathrm{rpm}$ for $10 \mathrm{~min}$. The supernatants were sonicated for $30 \mathrm{~min}$, then filtered through a $0.45 \mu \mathrm{m}$ polyvinylidene fluoride filter (Whatman $13 \mathrm{~mm}$ GD/X syringe filter; Whatman, Florham park, NL, USA) prior to total arsenic analysis. The method was validated by analysis of NIES CRM No.18. The total arsenic concentration of the reference material was detected to be $141.30 \pm 3.80 \mu \mathrm{g} / \mathrm{L}(n=5)$, which was within the range for the certified value of 
$137.00 \pm 11.00 \mu \mathrm{g} / \mathrm{L}$. After preparation, the acid-digested solution was diluted with ultra-pure water and introduced into an Agilent 7500a ICP-MS (Agilent Technologies, Santa Clara, CA, USA). The instrument settings were as follows: radio-frequency (RF) power, $1400 \mathrm{~W}$; argon plasma gas flow, $15 \mathrm{~L} / \mathrm{min}$; and carrier gas (argon) flow, $1.10 \mathrm{~L} / \mathrm{min}$. A concentric type nebulizer, nickel skimmer, and sample cones were used, and detection mass was set to $\mathrm{m} / \mathrm{z}$ of $75(75 \mathrm{As}+)$ and $77(40 \mathrm{Ar} 37 \mathrm{Cl}+)$. The instrument limit of detection (LOD) of aqueous arsenic standard solution and the method limit of quantitation (LOQ) were calculated according to the definition stipulated by Japanese Industrial Standards (JIS) [29]. The LOD and LOQ were calculated as 0.20 and $1.10 \mu \mathrm{g} / \mathrm{L}$, respectively.

\section{Determination of arsenic species in urine and saliva by HPLC-ICP-MS}

After centrifugation, the supernatant were diluted fiveand one-point-five-fold with ultra-pure water, respectively, and then filtered through a $0.45 \mu \mathrm{m}$ polyvinylidene fluoride filter (Whatman $13 \mathrm{~mm}$ GD/X syringe filter). After preparation, an Agilent 1100 HPLC series (Agilent Technologies) with a Dionex IonPac AS22 column $(250 \times 4.0 \mathrm{~mm}$ i.d., Thermo Fisher Scientific, Waltham, MA, USA) and an Agilent 7500a ICP-MS were used to separate and detect the arsenic species. The HPLC separation conditions were as follows: Mobile phase, $20 \mathrm{mM}$ NH4HCO3 (pH 10.0); Flow rate, $1.20 \mathrm{~mL} / \mathrm{min}$; Column temperature, $40{ }^{\circ} \mathrm{C}$, and Injection volume, $50 \mu \mathrm{L}$. The LOD of As ${ }^{\mathrm{III}}, \mathrm{As}^{\mathrm{V}}, \mathrm{MMA}, \mathrm{DMA}$, and AsBe were calculated as $0.90,0.50,0.70,0.70$, and $0.70 \mu \mathrm{g} / \mathrm{L}$, respectively. The AsBe and DMA concentrations in the CRM No.18 urine were $77.70 \pm 2.70 \mu \mathrm{g} / \mathrm{L}$ and $39.00 \pm$ $1.10 \mu \mathrm{g} / \mathrm{L}(n=5)$, and the values were within the ranges for certified value of $69.00 \pm 12.00$ and $36.00 \pm 9.00 \mu \mathrm{g} / \mathrm{L}$, respectively.

\section{Creatinine $(\mathrm{Cr})$ in urine}

Urinary creatinine was measured by Microplate Reader (BioTek Instruments, Inc., USA) using a Metra Creatinine Assay Kit (Beijing Kinghawk Pharmaceutical CO., LTD, China). Concentrations of total arsenic and its species in urine were normalized by urinary creatinine concentrations.

\section{Statistical analysis}

Data analysis was carried out using SPSS software (version 17.0, SPSS Inc., Chicago, IL, USA). The statistical significance for the different groups was determined using oneway analysis of variance (ANOVA) or Student's $t$-test. Histogram and normal probability plot of the arsenic concentration in drinking water and saliva revealed that the distributions were normality, and in urine it was right skewed and deviated from normality, so the bivariate associations were analyzed by Pearson and/or Spearman's rank correlation analysis. Any $p$-values less than 0.05 were considered statistically significant.

\section{Results and Discussion}

The characteristics of human subjects and distribution of total arsenic in drinking water

Arsenicosis has long be recognized as a major public health issue in the world and Shanyin County in Shanxi Province is one well known endemic area of severe arsenicosis in China [30, 31]. In the present study, 70 participants from 42 families in Shanyin County of Shanxi Province, China were recruited, and approximately half of them were male (37 males and $33 \mathrm{fe}$ males). The average age of the participants was 48 years old with the range from 21 to 78 . In addition, 42 well water samples were also collected from all families and analyzed the total arsenic by AFS-230, the highest and lowest concentrations of arsenic were determined to be $720.00 \mu \mathrm{g} / \mathrm{L}$ and $0.55 \mu \mathrm{g} / \mathrm{L}$, respectively. The median value of arsenic in drinking water samples was $127.22 \mu \mathrm{g} / \mathrm{L}$, and $66.67 \%$ of the arsenic levels exceeded the drinking water standard in China for arsenic $(50 \mu \mathrm{g} / \mathrm{L})$ [32], the results that were similar to our previous experimental results $[26,27]$ (Table 1).

\section{Total Arsenic concentration in saliva and urine of individuals}

The present study used ICP-MS to detect total arsenic in the saliva and urine of 70 individuals. The detection results showed that the median value of salivary arsenic and urinary arsenic was $12.31 \mu \mathrm{g} / \mathrm{L}$ and $124.93 \mu \mathrm{g} / \mathrm{gCr}$, respectively (Table 1). We divided the water arsenic concentrations into three groups: $<50(\mu \mathrm{g} / \mathrm{L}), 50 \sim 200(\mu \mathrm{g} / \mathrm{L})$ and $>200(\mu \mathrm{g} / \mathrm{L})$. Comparison of the arsenic concentrations in urine and saliva among the three groups showed that the urinary arsenic level increased gradually with an increase of the arsenic concentration in drinking water; the median values of urinary arsenic in the 3 groups were 53.20, 123.34 and $167.70 \mu \mathrm{g} / \mathrm{gCr}$, respectively. There was a significant difference among the 3 groups, $P<0.05$ (Table 1 ). Urinary arsenic is currently accepted as the biomarker of arsenic exposure. Our results also confirmed that urinary arsenic can reflect the level of exposure to arsenic, which was consistent with the results of urinary arsenic in children and adults exposed to arsenic in drinking water in Inner Mongolia as reported by Sun et al. [33]. Our study analyzed the total arsenic in human saliva of three groups, and found that, similar to urinary arsenic, with an increase in the arsenic concentrations in drinking water, the salivary arsenic level increased markedly as well. The median values of salivary arsenic in the 3 groups were 3.41 , 11.20 and $22.91 \mu \mathrm{g} / \mathrm{L}$, and the differences were significant $(P<0.05)$ (Table 1$)$. The present results were similar to 
Table 1 Distribution of total arsenic in drinking water, saliva and urine from individuals exposed to different levels of arsenic in drinking water in Shanyin County of Shanxi Province, China

\begin{tabular}{lllll}
\hline $\begin{array}{l}\text { Arsenic } \\
\text { levels in } \\
\text { drinking } \\
\text { water } \\
(\mu \mathrm{g} / \mathrm{L})\end{array}$ & $\begin{array}{l}\text { Skin lesions }(\mathrm{n}) \\
\text { Absent/Present }\end{array}$ & $\begin{array}{l}\text { Arsenic concentration }(\mu \mathrm{g} / \mathrm{L}) \\
\text { Median }(\text { Min } \sim \text { Max })(\mathrm{n})\end{array}$ & $\begin{array}{l}\text { Salivary arsenic }(\mu \mathrm{g} / \mathrm{L}) \\
\text { Median }(95 \% \mathrm{Cl})(\mathrm{n})\end{array}$ & $\begin{array}{l}\text { Urinary arsenic }(\mu \mathrm{g} / \mathrm{gCr}) \\
\text { Median }(95 \% \mathrm{Cl})(\mathrm{n})\end{array}$ \\
\hline$<50$ & $17 / 4$ & $11.15(0.55 \sim 41.86)(14)$ & $3.41^{\mathrm{a}}(0.96-18.54)(21)$ & $53.20^{\mathrm{a}}(7.53-330.71)(21)$ \\
$50-200$ & $10 / 12$ & $125.61(73.25 \sim 199.92)(13)$ & $11.20^{\mathrm{b}}(2.78-44.03)(22)$ & $123.34^{\mathrm{b}}(32.40-435.93)(22)$ \\
$>200$ & $6 / 21$ & $317.63(204.16 \sim 720.00)(15)$ & $22.91^{\mathrm{c}}(9.56-62.11)(27)$ & $167.70^{\mathrm{c}}(103.95-723.10)(27)$ \\
Sum & $33 / 37$ & $127.22(0.55 \sim 720.00)(42)$ & $12.31(1.86-46.62)(70)$ & $124.93(21.80-497.70)(70)$ \\
\hline
\end{tabular}

Values represent the median $(95 \% \mathrm{Cl})$. Statistical analysis using $t$-test. Median values within a column not sharing a common superscript letter $(\mathrm{a}, \mathrm{b}$, c) were significantly different, $P<0.05$

those of Yuan et al. [20] who analyzed the arsenic concentration in human saliva of 32 volunteers from Edmonton, Alberta, Canada, who had been exposed to background levels of arsenic less than $5 \mu \mathrm{g} / \mathrm{L}$ in drinking water. The mean value of the total arsenic in saliva was $0.79 \mu \mathrm{g} / \mathrm{L}$. However, the saliva samples were collected from 301 residents of Ba Men, Inner Mongolia, China, who were exposed to arsenic concentrations up to $826 \mu \mathrm{g} / \mathrm{L}$ in drinking water, and the mean value of the total arsenic in these samples was $11.9 \mu \mathrm{g} / \mathrm{L}$.

\section{Correlations among total arsenic concentrations in saliva, urine and drinking water}

The present study compared the total arsenic concentrations in urine and drinking water by Spearman's rank correlation analysis and revealed there was a significant positive association between them $(r=0.686, P<0.05)$. Comparison of the total arsenic in saliva and drinking water with Pearson correlation analysis also showed that, similar to urinary arsenic, there was an obvious positive association between them, the correlation coefficient was $0.674, P<0.05$. A previous study has reported that there was a good correlation between the arsenic concentrations in drinking water and in saliva $(r=0.610)$, as well as between the arsenic concentration in drinking water and in urine $(r=0.644)$ [34]. Additionally, we compared the total arsenic in saliva and urine with Spearman's rank correlation analysis and found that there was a significant positive correlation between them, the correlation coefficient was up to $0.794, P<0.05$ (Fig. 1). Our results were quite consisted with the report by Bhowmick et al., [35], who found that total arsenic concentration of saliva and urine also had a significant positive correlation by a case-control study in West Bengal, India. Their study also advocates that measurement of the forms of arsenic in saliva may additionally provide insight into the internal dose and any individual differences in susceptibility to arsenic exposure.

\section{Relationship between skin lesions and total arsenic in drinking water, urine and saliva}

Arsenic tends to concentrate in ectodermal tissue such as the skin, hair and nails, and thus, skin lesions (both malignant and non-malignant lesions) were considered to be the most common adverse health effects associated with chronic arsenic exposure in humans [36]. In the present study, trained medical doctors conducted detailed physical examinations according to the Diagnosis Standards on Arsenicosis of China [25] to identify cases of different skin lesions. The results showed that there were 37 individuals with varying degrees of skin lesions among the 70 objects. We divided the crowd into two groups according to the presence or absence of skin lesions, and compared the total arsenic concentrations in drinking water, urine and saliva between the two groups by Student's $t$-test. Table 2 showed the results of analysis indicating the concentrations of total arsenic in drinking water, urine and saliva in the group with skin lesions were significantly higher than those in the group with no skin lesions $(P<0.05)$. Before this study, a higher prevalence rate of arsenical skin lesions with a clear dose-response relationship was found among Bangladeshi populations ingesting arsenic contaminated water [37]. Additionally, Kile et al. [38] reported that there was a great risk of skin lesions associated with urinary arsenic. Our present results once again confirmed that there was an obvious correlation between skin lesions and arsenic present in drinking water and urine. It was worth mentioning that in the simultaneous analysis of the relationship between skin lesions and salivary arsenic, there was also a significant difference in salivary arsenic between the two groups, $P<0.05$ (Table 2). Furthermore, there was an obvious positive association between salivary arsenic and total arsenic in drinking water and urine, which suggested that the total arsenic in saliva can be used as an effective biomarker of arsenic exposure.

\section{Arsenic species in urine and saliva of individuals}

We quantified the arsenic species in urine and saliva samples of individuals using HPLC-ICP/MS. As shown in Fig. 2, $\mathrm{As}^{\mathrm{III}}, \mathrm{As}^{\mathrm{V}}, \mathrm{MMA}$, and DMA were detected in all of 


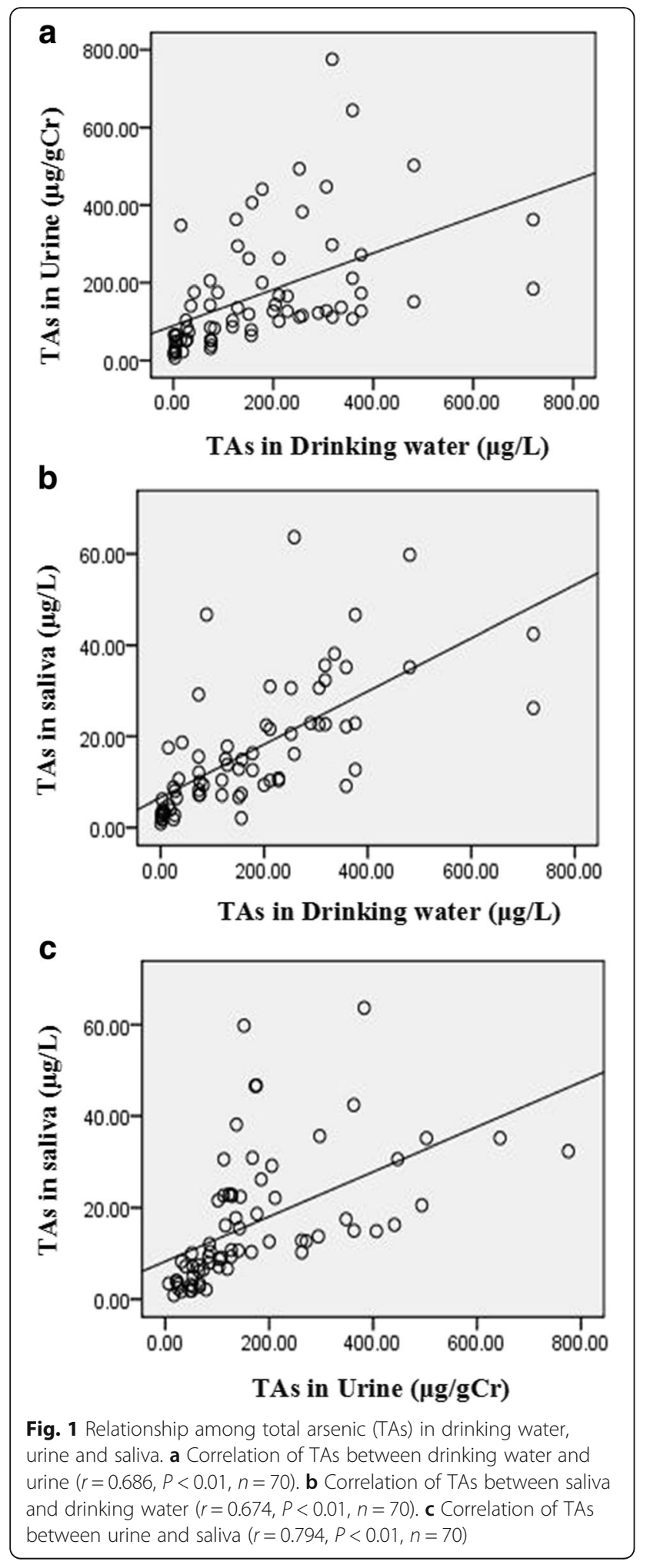

the urine samples, and in saliva samples, most of them contained detectable DMA and MMA, but the major species were iAs $\left(\mathrm{As}^{\mathrm{III}}+\mathrm{As}^{\mathrm{V}}\right)$. The median values of the four different species, sum As and total As levels between male and female were shown in Table 3. Comparison of urinary arsenic between male and female participants we can see that, even though the concentrations and distributions of As species in female were more higher than that of in male, there were no significant differences between them $(p>0.05)$, which was consisted with the study of Sun et al., [33]. However, Tseng et al., [39] detected the arsenic and its species in urine of 479 adults people (220 men and 259 women) found that women had a higher ability to methylate arsenic than men. The reason of these differences maybe because the sample individual numbers were fewer so we cannot exclude the possible contribution of gender differences in the study group. Besides, due to the demographic information of this study was limited, other influencing factors (e.g., age, BMI, living habits) of arsenic methylation capacity required to be further investigated.

Similar to urinary arsenic, there was also no significant differences between male and female in salivary total arsenic and its species ( $\mathrm{As}^{\mathrm{III}}, \mathrm{As}^{\mathrm{V}}, \mathrm{MMA}$, and DMA) as shown in Table 3. Both in male and female, there was good agreement between SumAs and TAs which were directly detected by ICP-MS.

\section{Comparison of the proportion of arsenic species and methylation indices in urine and saliva}

Even though some researchers had analyzed the total arsenic and arsenic species in human saliva, the comparison of arsenic species between urine and saliva has not yet been reported. Here, we analyzed the proportion of arsenic species and methylated indices in saliva and compared them with that of in urine for the first time. As shown in Table 4, the most excreted arsenic compound in urine was DMA, accounting for approximately $54.38 \%$ of the total, and the second excreted was MMA, about $23.14 \%$ of the total, there was only $21.65 \%$ of iAs $\left(\mathrm{As}^{\mathrm{III}}+\mathrm{As}^{\mathrm{V}}\right)$ species in urine samples. Which was consisted with the report by Hata et al., [40], who detected the arsenic and its species in urine of 165 married couples lived in the Pabna District in Bangladesh for more than 5 years, the iAs concentration in drinking water there was ranged $0.5-332 \mu \mathrm{gAs} / \mathrm{L}$ and the median value of arsenic species proportion in urine was DMA 73.2\%, MMA $10.9 \%$, iAs $15.9 \%$ respectively. However, in saliva samples, the proportion of arsenic species were obviously different with that of in urine samples. The most excreted arsenic compound in saliva was not DMA but iAs, the mean value of iAs proportion was $76.18 \%$, DMA and MMA proportion were only 13.08 and $9.13 \%$, respectively. Our results were similar to the study by Yuan et al., [20], who detected arsenic species for the first time in human saliva which was collected from 301 people lived in $\mathrm{Ba}$ Men, Inner Mongolia, China, where the drinking water also contained high levels of iAs. The mean percentages of individual arsenic species concentration over the mean 
Table 2 Relationship between skin lesions and total arsenic (TAs) concentrations in drinking water, urine and saliva

\begin{tabular}{lllll}
\hline Skin lesions & Numbers & Arsenic in drinking water $(\mu \mathrm{g} / \mathrm{L})$ & Urinary arsenic $(\mu \mathrm{g} / \mathrm{g} C r)$ & Salivary arsenic $(\mu \mathrm{g} / \mathrm{L})$ \\
\hline Absent & 33 & $111.99 \pm 19.14$ & $98.89 \pm 14.52$ & $9.21 \pm 1.26$ \\
Present & 37 & $225.97 \pm 30.12^{* *}$ & $233.69 \pm 28.91^{* *}$ & $23.18 \pm 2.53^{* *}$ \\
$t$ value & - & -3.194 & -4.167 & -4.938 \\
\hline
\end{tabular}

** $p<0.01$, compared with the skin lesions absent group, statistical analysis by Student's $t$-test

total arsenic concentration were: iAs85\%, MMA7\%, and DMA4\%. Subsequently, Lew et al., [23] analyzed arsenic species in saliva collected from 61 children who played on chromated copper arsenate (CCA) and non-CCA playgrounds also found that iAs was the most excreted arsenic compound.

Besides, the primary methylation index (PMI) and second methylation index (SMI) in saliva were also significantly lower than that of in urine (Table 4). Suggested that most of the arsenic in saliva maybe not be metabolized and methylated. In our previous publications, we also found that saliva assay can be used as a useful tool for biological monitoring of total arsenic exposure, however, after consumption of organic arsenic (Chinese Seaweed), six species were detected in urine but only three species were detected in saliva samples, and most of them are unmethylated [41].

To further confirm the relationship of arsenic species and methylated indices between saliva and urine, we analyzed the correlation among them by Pearson's correlation coefficient, unlike the obvious positive correlation of total arsenic in urine and saliva, no significant correlation were observed among the proportion of four species in urine and saliva (data not shown). As we all know that urine is considered as a surrogate for assessing arsenic metabolism in human body [42]. The low proportion of methylated arsenic species (MMA, DMA) in saliva and negative relationship with urine found in the present research suggested that although total arsenic level in human saliva can be used as a new biomarker of arsenic exposure, saliva may be not an efficient tool for understanding the metabolism of arsenic in the body. Hines et al., [43] analyzed serum, saliva, urine, and milk for the oxidative phthalate metabolites of 33 lactating North Carolina women also found that phthalate metabolites are most frequently detected in urine, but unlikely to be detectable in milk and saliva.

\section{Benefits of saliva as a biomonitoring tool for assessing total arsenic exposure}

The use of saliva as a biomonitoring tool for assessing total arsenic exposure has several benefits compared with other current biomonitoring tools. For example, researchers often can not directly collect urine samples due to personal privacy issues, therefore, it is difficult to ensure the authenticity of samples [44]. In contrast, saliva samples can be easily collected, and particularly advantageous when children and menstruating women are involved. Blood may be the best tissue for monitoring most pollutants, but it is not suitable for arsenic monitoring because the half-life of arsenic and its compounds in blood is very short as most eliminated from the blood in a few hours [45]. In addition, the composition of blood is quite complex and its collection is invasive.

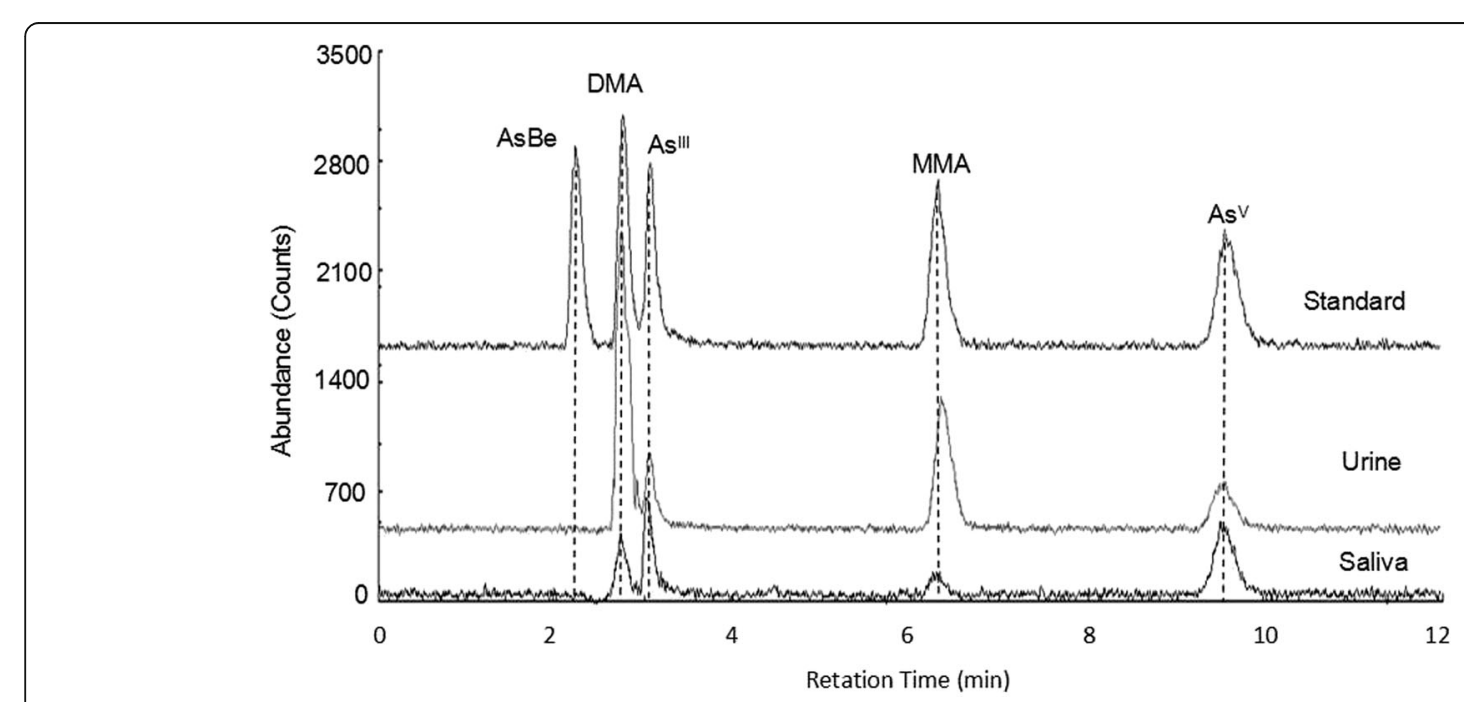

Fig. 2 Chromatograms of arsenic species in the standard solution, urine sample and saliva sample obtained using HPLC-ICP-MS 
Table 3 Concentrations of different arsenic species, Sum As and total arsenic (TAs) in urine and saliva samples

\begin{tabular}{|c|c|c|c|c|}
\hline & Urine As ( $\mu \mathrm{g} / \mathrm{gCr}$ ) & & Saliva As ( $\mu \mathrm{g} / \mathrm{L})$ & \\
\hline & Median (95\%Cl) & & Median (95\%Cl) & \\
\hline & Male (37) & Female (33) & Male (37) & Female (33) \\
\hline$A s^{I I I}$ & $14.3(2.76-34.44)$ & $16.60(2.72-46.90)$ & $10.08(1.42-35.59)$ & $8.78(1.83-29.73)$ \\
\hline$A s^{V}$ & $18.15(4.53-55.58)$ & $21.85(4.28-54.74)$ & $7.51(1.78-19.00)$ & $3.27\left(N^{*}-15.05\right)$ \\
\hline MMA & $35.15(6.24-101.22)$ & $40.8(9.4-167.76)$ & $2.14(0.70-3.34)$ & 1.73 (ND-3.35) \\
\hline DMA & $85.75(10.23-238.00)$ & $103.60(18.52-432.48)$ & $3.03(1.14-7.28)$ & $1.83(1.24-5.69)$ \\
\hline Sum $A s^{a}$ & $153.45(24.96-429.24)$ & $198.45(37.60-687.00)$ & $28.23(6.82-43.05)$ & $22.14(6.55-34.86)$ \\
\hline$T A s^{b}$ & $164.37(27.05-447.24)$ & $205.84(48.25-775.73)$ & $26.34(3.32-63.67)$ & $19.51(1.90-35.61)$ \\
\hline
\end{tabular}

${ }^{a}$ Values are concentrations of sum of arsenic compounds detected in speciation analysis by HPLC-ICP-MS; ${ }^{\mathrm{b}}$ Values are total arsenic concentrations directly determined by ICP-MS; * ND, not detected (bellow LOD)

However, the arsenic in saliva is relatively stable and the collection method for saliva is simple and non-invasive [41], which makes it more suitable for population studies. Hair and nail samples are easy to collect, but they are vulnerable to contamination by external environmental pollutants, so it is difficult to accurately determine the exposure dose for arsenic in the body [46]. Compared with hair and nail samples, saliva samples are less affected by external interference.

\section{Limitation of saliva as a biomonitoring tool for assessing arsnenic metabolites in human body}

Different with the strong positive correlation of total arsenic in saliva and urine, for arsenic metabolites, obviously

Table 4 Proportion of different arsenic species (DMA, MMA, $A s^{\prime \prime \prime}$, and $A s^{V}$ ) and methylation indices in urine and saliva samples

\begin{tabular}{|c|c|c|c|c|c|c|}
\hline & \multicolumn{4}{|c|}{ Proportion (\%) } & \multicolumn{2}{|c|}{ Methylation indices } \\
\hline & $\overline{D M A}$ & MMA & $A s^{I I I}$ & $\mathrm{As}^{\mathrm{V}}$ & $\overline{\mathrm{PMI}^{\mathrm{a}}}$ & $\mathrm{SMI}^{\mathrm{b}}$ \\
\hline \multicolumn{7}{|l|}{ Urine Samples } \\
\hline Mean & 54.38 & 23.14 & 8.98 & 12.67 & $0.78^{* *}$ & $0.7^{*}$ \\
\hline Std. Deviation & 1.02 & 0.32 & 0.40 & 0.69 & 0.01 & 0.01 \\
\hline \multicolumn{7}{|l|}{ Percentiles } \\
\hline 25 & 50.40 & 22.09 & 7.47 & 11.05 & 0.74 & 0.68 \\
\hline 50 & 55.21 & 23.35 & 9.11 & 12.46 & 0.78 & 0.71 \\
\hline 75 & 57.60 & 24.29 & 10.39 & 15.22 & 0.8 & 0.72 \\
\hline \multicolumn{7}{|l|}{ Saliva Samples } \\
\hline Mean & 13.08 & 9.13 & 48.22 & 27.97 & 0.22 & 0.55 \\
\hline Std. Deviation & 1.41 & 1.12 & 5.43 & 3.17 & 0.02 & 0.05 \\
\hline \multicolumn{7}{|l|}{ Percentiles } \\
\hline 25 & 6.01 & 6.35 & 30.81 & 11.79 & 0.06 & 0.51 \\
\hline 50 & 15.78 & 9.16 & 33.85 & 33.78 & 0.25 & 0.6 \\
\hline 75 & 17.38 & 14.08 & 86.79 & 39.75 & 0.32 & 0.67 \\
\hline
\end{tabular}

Primary methylation index (PMI) calculated from (MMA + DMA)/total As (TAs), ${ }^{\mathrm{b}} \mathrm{Secondary}$ methylation index (SMI) calculated from DMA/(MMA + DMA) [33]

${ }^{*} p<0.05,{ }^{* *} p<0.01$, compared with mean value in saliva samples by Student's $t$-test different distribution of the four main arsenic species ( $\mathrm{As}^{\mathrm{III}}, \mathrm{As}^{\mathrm{V}}, \mathrm{MMA}$, and DMA) between saliva and urine was found in the present study. For urinary arsenic, the most excreted compounds were methylated arsenic (DMA and MMA), only about $10 \% \sim 20 \%$ of iAs was existed both in our data and other reports [33, 39, 40]. However, in the same individual, only about $20 \%$ of methylated compounds (DMA and MMA) were detected in saliva samples, and some of them were not detected, conversely, iAs compound percentage was as high as $76 \%$. Besides, arsenic level in saliva was also considered to be lower and small variation [24] which renders further identifying the kinds of its species difficult. However, in another study reported by Bhowmick et al., [47] showed that, the dominant fraction of As in saliva consists of inorganic As but, interestingly, significant associations were observed between the total daily As intake and the concentrations of methylated species in the saliva samples. Thus, whether or not saliva can be used as an efficient tool for assessing arsenic metabolites in humans exposed to arsenic requires further investigation.

\section{Conclusions}

In summary, the present study has shown that total arsenic concentration in saliva exists a strong positive correlation with total urinary arsenic, drinking water arsenic and different skin lesions. Furthermore, the collection method for saliva is simple and non-invasive, which makes it can be used as a new biomarker for monitoring total arsenic exposure in the crowd. For arsenic speciation analysis, different with urinary arsenic species, most arsenic species in saliva are not methylated. The PMI, SMI and proportion of the four different species ( $\mathrm{As}^{\mathrm{III}}, \mathrm{As}^{\mathrm{V}}, \mathrm{MMA}$, and DMA) in saliva showed a poor relationship with that of in urine. In addition, the concentration of arsenic in saliva are considerably lower than in urine, which renders further identifying the kinds of its metabolites difficult. Thus, saliva assay is probably a useful tool for biological monitoring of total arsenic exposure in the crowd rather 
than an efficient tool for assessing arsenic metabolites in humans exposed to arsenic.

\section{Abbreviations}

ANOVA: One-way analysis of variance; AsBe: Arsenobetaine; Aslll: Sodium arsenite; AsV: Sodium arsenate; CCA: Chromated copper arsenate; Cr: Creatinine; DMA: Dimethylarsinate; HPLC-ICP/MS: High-performance liquid chromatography-inductively coupled plasma-mass spectrometry; IARC: International agency for research on cancer; LOD: Limit of detection: LOQ: Limit of quantitation; MMA: Methylarsonic acid; PMI: Primary methylation index; SMI: Second methylation index

\section{Acknowledgments}

Not applicable.

\section{Funding}

This study was supported in part by the National Natural Science Foundation of China (NSFC) research grant (No. 81573173; 81660525; 81473008; 81673203) and the University Science Research Project of Jiangsu Province (16KJB330009).

\section{Availability of data and materials}

Please contact author for data requests.

\section{Authors' contributions}

Wang DP, Wang SX, Wang ZH and An Y participated in the sample collection; Wang DP, Shimoda Y and Yamanaka K carried out the total arsenic and speciation analyses in urine and saliva samples; Liu J, Liu X, Jin HY and Gao FF participated in the performing of experiments; Wang DP and An Y conceived of the study and drafted the manuscript; Zhang J, Yamanaka $Y$ and Tong $J$ participated in its design and coordination and helped to draft the manuscript. All authors read and approved the final manuscript.

\section{Competing interests}

The authors declare that they have no competing interests.

\section{Consent for publication}

Not applicable.

\section{Ethics approval and consent to participate}

This study was approved by the Ethics Committee of the School of Public Health, Medical College of Soochow University according to the recommendations of the World Medical Association Declaration of Helsink Ethical Principles for international health research. All participants provided informed consent before participating.

\section{Publisher's Note}

Springer Nature remains neutral with regard to jurisdictional claims in published maps and institutional affiliations.

\section{Author details \\ ${ }^{1}$ Department of Toxicology, School of Public Health, Jiangsu Key Laboratory of Preventive and Translational Medicine for Geriatric Diseases, Medical College of Soochow University, Suzhou, Jiangsu 215123, People's Republic of China. ${ }^{2}$ Key Laboratory of Environmental Pollution Monitoring and Disease Control, Ministry of Education, Department of Toxicology, School of Public Health, Guizhou Medical University, Guiyang, Guizhou, China. ${ }^{3}$ Laboratory of Environmental Toxicology and Carcinogenesis, School of Pharmacy, Nihon University, Chiba, Japan. ${ }^{4}$ Shanxi Institute for Prevention and Treatment of Endemic Disease, Linfen, Shanxi, People's Republic of China.}

Received: 24 January 2017 Accepted: 20 April 2017

Published online: 11 May 2017

\section{References}

1. Cullen WR, Reimer KJ. As speciation in the environment. Chem Rev. 1989;89:713-74.

2. Singh AP, Goel RK, Kaur T. Mechanisms pertaining to arsenic toxicity. Toxicol Int. 2011;18:87-93.
3. IARC. Working Group on the Evaluation of Carcinogenic Risks to Humans. Arsenic, metals, fibres, and dusts. A review of human carcinogens. Lyon, France. 2012; 100 C: 36-93.

4. Surdu S, Fitzgerald EF, Bloom MS, Boscoe FP, Carpenter DO, Haase RF, et al. Occupational exposure to arsenic and risk of nonmelanoma skin cancer in a multinational European study. Int J Cancer. 2013;133:2182-91.

5. Gilbert-Diamond D, Li Z, Perry AE, Spencer SK, Gandolfi AJ, Karagas MR. A population-based case-control study of urinary arsenic species and squamous cell carcinoma in New Hampshire, USA. Environ Health Perspect. 2013:121:1154-60

6. Tsujia JS, Perezb V, Garrya MR, Alexander DD. Association of low-level arsenic exposure in drinking water with cardiovascular disease: a systematic review and risk assessment. Toxicol. 2014;323:78-94.

7. Navas-Acien A, Silbergeld EK, Pastor-Barriuso R, Guallar E. Arsenic exposure and prevalence of type 2 diabetes in US adults. JAMA-J Am Med Assoc. 2008:300:814-22.

8. WHO, Arsenic in Drinking-Water. Background document for development of WHO guidelines for drinking-water quality. Geneva: World Health Organization; 2011.

9. Naujokas MF, Anderson B, Ahsan H, Vasken Aposhian H, Graziano JH, Thompson C, Suk WA. The broad scope of health effects from chronic arsenic exposure: update on a worldwide public health problem. Environ Health Perspect. 2013;121:295-302

10. Hubaux R, Becker-Santos DD, Enfield KS, Rowbotham D, Lam S, Lam WL, Martinez VD. Molecular features in arsenic-induced lung tumors. Mol Cancer. 2013;12:20.

11. Ren XF, McHale CM, Skibola CF, Smith AH, Smith MT, Zhang L. An emerging role for epigenetic dysregulation in arsenic toxicity and carcinogenesis. Environ Health Perspect. 2010;119:11-9.

12. Hughes MF. Biomarkers of exposure: a case study with inorganic arsenic. Environ Health Perspect. 2006;114:1790-6.

13. Chen CJ, Hsu LI, Wang CH, Shih WL, Hsu YH, Tseng MP, et al. Biomarkers of exposure, effect, and susceptibility of arsenic-induced health hazards in Taiwan. Toxicol Appl Pharm. 2005;206:198-206.

14. Chiappin S, Antonelli G, Gatti R, Palo EF. Saliva specimen: a new laboratory tool for diagnostic and basic investigation. Clin Chim Acta. 2007:383:30-40.

15. Almeida GRC, Freitas CU, Barbosa Jr F, Tanus-Santos JE, Gerlach RF. Lead in saliva from lead-exposed and unexposed children. Sci Total Environ. 2009:407:1547-50.

16. Timchalk C, Lin Y, Weitz KK, Wu H, Gies RA, Moore DA, Yantasee W. Disposition of lead $(\mathrm{Pb})$ in saliva and blood of Sprague-Dawley rats following a single or repeated oral exposure to $\mathrm{Pb}$-acetate. Toxicology. 2006:222:86-94

17. Talio MC, Luconi MO, Masi AN, Fernández LP. Cadmium monitoring in saliva and urine as indicator of smoking addiction. Sci Total Environ. 2010;408:3125-32

18. Fakour H, Esmaili-Sari A, Zayeri F. Scalp hair and saliva as biomarkers in determination of mercury levels in Iranian women: Amalgam as a determinant of exposure. J Hazard Mater. 2010:177:109-13.

19. Denovan LA, Lu C, Hines CJ, Fenske RA. Saliva biomonitoring of atrazine exposure among herbicide applicators. Int Arch Occup Enviorn Health. 2000;73:457-62.

20. Yuan CG, Lu XF, Oro N, Wang ZW, Xia YJ, Wade TJ, et al. Arsenic speciation analysis in human saliva. Clin Chem. 2008;54:163-71.

21. Bhowmick S, Halder D, Kundu AK, Saha D, Iglesias M, Nriagu J, Chatterjee D. Is saliva a potential biomarker of arsenic exposure? a case-control study in west Bengal, India. Environ Sci Technol. 2013;47:3326-32.

22. Hinhumpatch P, Navasumrit P, Chaisatra K, Promvijit J, Mahidol C, Ruchirawat M. Oxidative DNA damage and repair in children exposed to low levels of arsenic in utero and during early childhood: application of salivary and urinary biomarkers. Toxicol Appl Pharm. 2013;273:569-79.

23. Lew K, Acker JP, Gabos S, Le XC. Biomonitoring of arsenic in urine and saliva of children playing on playgrounds constructed from chromated copper arsenate-treated wood. Environ Sci Technol. 2010;44:3986-91.

24. Fängström B, Moore S, Nermell B, Kuenstl L, Goessler W, Grandér M. Breastfeeding protects against arsenic exposure in Bangladeshi infants. Environ Health Perspect. 2008;116:963-9.

25. Ministry of Health. Diagnosis Standards on Arsenicosis of China. Beijing: Ministry of Health of the People's Republic of China; 2001. 
26. Li Z, Wang SX, Wang ZH, Wang T, Qiao XY, Zhang XD. Arsenic levels in external environment in endemic arsenism area of Shanxi province. Chin J Ctrl Endem Dis. 2008;23:270-1.

27. Li Z, Wang SX, Wang ZH, Wang T, Qiao XY, Zhang XD. The relationship between arsenic in drinking water and skin lesions in endemic arsenism area in Shanyin County of Shanxi Province. Chin J Endemiol. 2009:28:88-90.

28. World Medical Association Declaration of Helsinki Ethical Principles for Medical Research Involving Human Subjects. Chin J Integr Med. 2001;7(3):3043-5.

29. Japanese Industrial Standards. High frequency plasma mass spectrometry general notice, K0133. In: JIS Handbook (Japanese Industrial Standards, Ed.). Tokyo: Japan Standards Association; 2006. p. 371-88.

30. Sun GF. Arsenic contamination and arsenicosis in China. Toxicol Appl Pharm. 2004;198:268-71.

31. Yu GQ, Chen Z, Zhao LJ, Sun DJ. The analysis of epidemic trends of endemic arsenicosis in China. Chin J Endemiol. 2010;29:3-8.

32. Ministry of Health. Standards for Drinking Water Quality. GB5749-2006. Beijing: Ministry of Health of the People's Republic of China; 2006.

33. Sun GF, Xu YY, Li X, Jin YP, Li B, Sun XC. Urinary arsenic metabolites in children and adults exposed to arsenic in drinking water in inner Mongolia, China. Environ Health Perspect. 2007;115:648-52.

34. Lew K, Yuan CG, Acker JP, Le XC. Salivary arsenic as a biomarker for arsenic exposure. Cell Biol Toxicol. 2008;24:367-71.

35. Bhowmick S, Halder D, Nriagu J, Guha Mazumder DN, Roman-Ross G, Chatterjee $D$, Iglesias M. Speciation of arsenic in saliva samples from a population of West Bengal, India. Environ Sci Technol. 2014;48(12): 6973-80.

36. Yu HS, Liao WT, Chai CY. Arsenic carcinogenesis in the skin. J Biomed Sci. 2006;13:657-66.

37. Tondel M, Rahman M, Magnuson A, Chowdhury IA, Faruquee MH, Ahmad SA. The relationship of arsenic levels in drinking water and the prevalence rate of skin lesions in Bangladesh. Environ Health Perspect. 1999;107:727-9.

38. Kile ML, Hoffman E, Rodrigues EG, Breton CV, Quamruzzaman Q, Rahman MA. Pathway-based analysis of urinary arsenic metabolites and skin lesions. Am J Epidemiol. 2011;173:778-86.

39. Tseng $\mathrm{CH}$, Huang YK, Huang YL, Chung CJ, Yang MH, Chen CJ. As exposure, urinary as speciation, and peripheral vascular disease in blackfoot diseasehyperendemicvillages in Taiwan. Toxicol Appl Pharmacol. 2005;206:299-308.

40. Hata A, Yamanaka K, Habib MA, Endo Y, Fujitani N, Endo G. Arsenic speciation analysis of urine samples from individuals living in an arseniccontaminated area in Bangladesh. Environ Health Prev Med. 2012;17:235-45.

41. Wang D, Shimoda Y, Kurosawa H, Liu J, Xu XG, Liu X, Jin HY, Tong J, Yamanaka K, An Y. Excretion patterns of arsenic and its metabolites in human saliva and urine after ingestion of Chinese seaweed. Int J Environ Anal Chem. 2015;95(5):1-11.

42. Orloff $\mathrm{K}$, Mistry $\mathrm{K}$, Metcalf $\mathrm{S}$. Biomonitoring for environmental exposures to arsenic. J Toxicol Environ Health, Part B. 2009;12:509-24.

43. Hines EP, Calafat AM, Silva MJ, Mendola P, Fenton SE. Concentrations of phthalate metabolites in milk, urine, saliva, and serum of lactating North Carolina women. Environ Health Perspect. 2009;117:86.

44. Schramm W, Smith RH, Craig PA. Drugs of abuse in saliva: a review. J Anal Toxicol. 1992:16:1-9.

45. National Research Council (US). Subcommittee on Arsenic in Drinking Water. Arsenic in drinking water. Washington, DC: National Academies Press; 1999

46. Thomas HJ. Arsenic, its clinical and environmental significance. J Trace Elem Exp Med. 2000;13:165-72.

47. Bhowmick S, Halder D, Nriagu J, Guha Mazumder DN, Roman-Ross G, Chatterjee $D$, Iglesias M. Speciation of arsenic in saliva samples from a population of West Bengal, India. Environ Sci Technol. 2014;48(12):6973-80.

\section{Submit your next manuscript to BioMed Central and we will help you at every step:}

- We accept pre-submission inquiries

- Our selector tool helps you to find the most relevant journal

- We provide round the clock customer support

- Convenient online submission

- Thorough peer review

- Inclusion in PubMed and all major indexing services

- Maximum visibility for your research

Submit your manuscript at www.biomedcentral.com/submit
Biomed Central 